ENTREVISTA 



\title{
Cristina Rodríguez Cabral: el proceso continuo de la identidad y su proyección poética*
}

\author{
Por Silvia Valero ${ }^{1}$ \\ Universidad de Cartagena (Colombia)
}

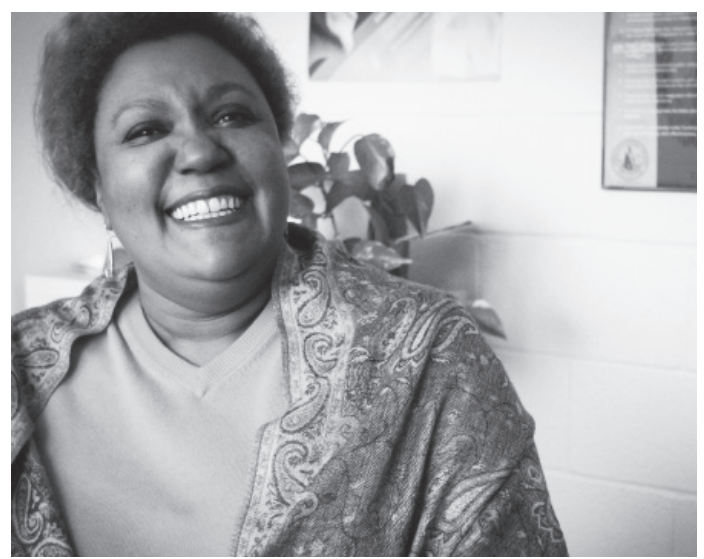

Cristina Rodríguez Cabral nació en Montevideo, en 1959, un año después de la muerte de la primera poetisa afro-uruguaya, Virginia Brindis de Salas. Al igual que ésta, su figura como poeta y su obra permanecen desconocidas en la región, a pesar de que ha escrito nueve libros de poesía, gran parte de los cuales ha sido recopilada en la antología Memoria y resistencia, del 2004: Pájaros sueltos (Uruguay, 1987); Entre giros y mutaciones (Uruguay, 1988); Desde el sol (Brasil, 1989); La del espejo y yo y De par en par (Uruguay, 1989); Quinientos años después y hoy más que nunca (Uruguay, 1992); Desde mi trinchera (1993); Pedirán más (Uruguay, 1996); Memoria y resistencia (1998); Noches sin luna, días con sol (1999). Luego de su paso, durante su juventud, por Brasil, donde comenzó su viaje introspectivo, y cuya expresión simbólica fue la obra Bahía, mágica Bahía (Premio Casa de las Américas, 1986), retornó a Uruguay, para trasladarse, tiempo después, a Estados Unidos, país donde reside desde entonces y trabaja como profesora universitaria.

Las primeras obras de Rodríguez Cabral se centran en el amor, los sentimientos íntimos y la experiencia de la mujer negra hispana (De Costa-Willis, 2003), pero será en las obras posteriores a 1995

\footnotetext{
* Cristina Rodríguez Cabral: The continuous process of identity and its poetic projection.

${ }^{1}$ Doctora en Literatura por la Universidad de Montreal (Canadá). Profesora del Programa de Lingüística y Literatura de la Universidad de Cartagena (Colombia). e-mail: svalero@unicartagena.edu.co
} 
que dé cuenta de su militancia social, su conciencia del racismo y la renovación de sus identificaciones culturales.

El relato de Cristina Rodríguez Cabral en esta entrevista no habla de etnicidades fijas ni pre-establecidas, sino de las múltiples fuentes que contribuyeron en ese proceso de conformación cultural y su consecuente producción poética. De este modo, el testimonio del camino que atravesó la poeta en los últimos veinte años, se proyecta, en parte, en su obra y se continúa aquí con su propia voz, dando cuenta, al mismo tiempo, de la capacidad reflexiva que le permite manifestar una evolución en su pensamiento en relación con algunos temas expuestos en entrevistas realizadas años atrás. Asume, en algún punto, un locus de enunciación que coincide, en algunos aspectos, con las identidades políticas que alcanzaron su apogeo en América Latina a partir de los años noventa, así como su proyección en el mundo de la literatura (cf. Valero, 2015). En este sentido, la poeta confiesa que debió abandonar su ámbito montevideano para, por un lado, tomar conciencia de una realidad ignorada por ella misma, en cuanto a las condiciones sociales de la comunidad negra de su país con la que no mantenía ningún vínculo, y por otro, asumir una afroetnicidad que hasta ese momento no había formado parte de su subjetividad. Sin embargo, y sin abandonar esta conciencia, hoy entiende que la lucha debe exceder la problemática racial ${ }^{2}$.

En la década de 1980 Cristina Rodríguez viaja a Brasil, y, a partir de allí, su vida, no solo profesional sino también personal, tomará un rumbo impensado hasta ese momento. "Mi experiencia en Uruguay", afirma, "fue muy sui generis, porque mi familia no vive en el barrio negro, digamos, tampoco pertenece a la clase baja, y eso... Me aisló de lo afro en Uruguay. En otras palabras, yo tenía una mirada blanca, iba a un colegio de monjas donde era la única negra y yo nunca me di cuenta de ser diferente".

\section{-¿No sentiste nunca ningún grado de prejuicio?}

Tuvo que haber habido, pero no fue nada que me abofeteara, que me despertara... Ahora pienso que no hay posibilidad de que en un colegio de monjas una sola negra no haya tenido un signo de racismo o de discriminación.

\footnotetext{
${ }^{2}$ Me refiero a la concepción de comunidad que elabora Cristina Rodríguez Cabral. En la entrevista con Lorna V. Williams, "Entrevista con Cristina Rodríguez Cabral en Montevideo en julio de 1993" (1995), la poeta define a su comunidad "en un sentido amplio [...] me refiero a todos los negros" (61). En el presente, como se verá más adelante en nuestra entrevista, sin negar las acciones e ideologías racistas antinegras actuales, extiende su comunidad a "lo humano".
} 
-Entonces, tu mirada sobre las comunidades negras de Montevideo se vería atravesada por las mismas improntas de tus compañeras.

Lamentablemente, sí, era la misma mirada con que creo que las ven los blancos uruguayos. Yo estaba totalmente separada de ellos, no porque eran negros sino porque pertenecían a otra clase social. Ahora creo que va todo junto, que es que pertenecen a otra clase social y que son negros.

-Pero luego de eso llegaría el primer contacto profundo con las comunidades negras, aunque brasileñas, que te provocaría un impacto vital...

Sí. Fue un viaje de búsqueda existencial a Brasil. Por eso en mi obra es algo clave. Me fui a los 25 o 26 años, pero fue mi primer viaje sola en la vida.

Hoje eu senti a Bahia cantar pra mim/e sambei com você,/ e vi sorrir pra mim/ e beijei seu sorriso,/ senti os nossos passos encontrando-se/ na rua,/ fazendo amor./ 0 cheiro das minhas fontes/ é o mesmo que das suas ondas,/ de seu mar [...]/ Salve Rainha, salve Nossa Senhora,/salve a Bahia sempre tão dentro de mim,/ agora ainda mais forte. (De Bahía, Mágica Bahía, 1985)

\section{-¿Por qué elegiste Brasil?}

En realidad fue un viaje a partir de una situación trágica. Tenía un novio que se había ido a Bahía y había vuelto maravillado, y poco después de regresar, murió. Yo estaba en estado de shock y me convencí de que me iba a morir también, y como me quedaba poco tiempo de vida, decidí hacer el mismo camino que él. Se había ido por una semana o dos y yo me quedé tres meses. Llegué ahí, conocí a otra persona, pero sobre todo descubrí mi negritud. Nunca me había hecho ningún cuestionamiento étnico hasta que estuve en Brasil y ahí me empecé a acercar al movimiento negro, a la literatura negra brasileña.

\section{-¿A quiénes leías?}

A Enrique Cunha, Oliveira Silveira, Paulo Colina, Ele Semog, la gente que forma parte del grupo literario Quilombhoje San Pablo, de los 
Cuadernos negros ${ }^{3}$ de San Pablo, los escritores que están en Río Grande del Sur liderados por Silveira. De Bahía, Jaime Sodré, escritor que estaba en la universidad estatal de Bahía. Su escritura era sobre la cuestión racial, pero con problemática actual. Yo siempre leía sobre la esclavitud, pero estos hablaban, por ejemplo, de que no podían entrar en la universidad. Todo un grupo de escritores de denuncia social, un grupo que trabajaba la autoestima del negro en el Brasil, para eliminar la mentalidad de favela y tratar de potenciar sus posibilidades. Cunha era profesor de la universidad, uno de los pocos en ese momento. Me nutría con esa gente. De ahí paso a África.

\section{-Ah, fue un doble descubrimiento.}

Sí, descubrí a los escritores del África portuguesa. Angolanos y mozambiqueños, sobre todo. Conocí a varios de ellos en Brasil, como Agostinho $\mathrm{Neto}^{4}$. No sabía que el primer presidente de Angola era poeta, que muchos escritores de Mozambique estaban en el gobierno. Me preguntaba por qué allí estaban tan insertos en la política y aquí no. Vi que eran escritores conocidos en sus países. Cuando volví a Uruguay, me acerqué a la Fundación de la Cultura Africana Agostinho Neto. Era una fundación dirigida por uruguayos que habían estado exiliados en Angola y estaba apoyada por la embajada de ese país. De ahí que teníamos el material literario de toda el África lusófona. Agostinho fue el primer presidente de Angola independiente y su mayor poeta. Entonces propuse hacer un taller literario para empezar a dar a conocer a esos escritores y hablar de la literatura del África lusitana. Las embajadas nos enviaron libros e hicimos una biblioteca. Los estudiantes eran, en general, de Antropología y de Historia, porque eran los más preparados.

\section{-Todavía había un gran desconocimiento desde el ámbito literario por esos temas.}

Claro, la gente de literatura no tenía ninguna base sobre los códigos literarios africanos ni sobre la historia de África. Tal vez por eso no les interesaba tampoco.

\footnotetext{
${ }^{3}$ A partir de 1978, se organizan, en San Paulo, un grupo de escritores con el objetivo de publicar anualmente sus poemas. Hasta 2004 se editarán los Cuadernos negros para hablar de la cultura y la lucha por la superación de las desigualdades raciales. Será recién a partir de la quinta edición de Cuadernos negros, en 1982, que el grupo de poetas se constituya como grupo Quilombhoje.

${ }^{4}$ Agostinho Neto dirigió el Movimiento Popular para la Liberación de Angola (MPLA) y tuvo una acción decisiva en la liberación de su país. En 1975 asumió la presidencia de la nación debiendo resistir la avanzada de los países colonialistas e imperialistas (Nota de la entrevistadora).
} 
-Vos decís que llegás a Brasil y comenzás a adquirir conciencia étnica. Entonces es algo de lo que te que vas apropiando, que no forma parte de tus orígenes familiares cercanos

Hubo de todo. Fue un despertar, porque, por ejemplo, mi abuelo fue historiador y fundador de la primera revista negra uruguaya, Nuestra $r a z a^{5}$, que fue la que más duró. Y ellos sí tenían una conciencia étnica. Casi no uso el término racial, porque... Ya a esta altura no sé lo que significa... Se usa mucho el término étnico por lo cultural, el autopercibirse como negro y compartir algunos valores propios de la comunidad negra.

\section{-¿Por ejemplo?}

Por ejemplo, el candombe. Pero hoy por hoy el candombe es música nacional. Vas a la salida de los tambores que salen todos los fines de semana en todos los barrios, ya no solo en el barrio de negros. Entonces es un poco complejo el fenómeno que se da allá. Los tambores no es una cosa exclusiva de los negros, sino compartida por todos los uruguayos. A mí a veces me pueden tildar, y quizás con cierta justicia, de que no pueda percibir totalmente los factores raciales en el Uruguay, porque toda mi educación, fue, ya te dije... De hecho, hasta el 2004, era la única persona negra en el Uruguay con un doctorado. Entonces, mi educación fue blanca...

\section{-Jamás habías ido a una llamada.}

A la llamada iba como podía ir cualquier otro blanco.

\section{-Pero sin asumirlo como parte de una "identidad racial".}

No, no, no, no era lo mío. Era lo mío en cuanto uruguaya, pero no en cuanto negra. Ahora lo percibo diferente, pero en aquellos momentos, no. Por ejemplo, vuelvo a Montevideo y mi hija no va a los tambores. Mi madre no fue nunca.

-¿Por qué?

Ay, porque no soportaba eso.

-“Cosa de negros”...

\footnotetext{
${ }^{5}$ Se refiere a Elemo Cabral (1887-1969), fundador, junto con los hermanos Barrios, de la revista Nuestra Raza (1933-1948). Además formó parte del Partido Autóctono Negro (1933-1948).
} 
Exactamente. Porque dentro de la comunidad negra había un división entre el negro usted y el negro che. El negro che era el que salía con los tambores y la botella de vino. El negro usted iba a la universidad. Y jamás se mezclaba con el otro. Y mi madre eso me lo puso muy claramente durante mi juventud. Cuando yo empiezo a ir al Barrio Sur, que era el barrio de los negros y empiezo a darme con la gente y entrar en todo eso, lo hago sola, y entro por esa visión que había traído de Brasil

\section{¿¿Y con qué te encontraste?}

Lo que me daba lástima era el estado de ignorancia de los afrouruguayos en cuanto al grado de discriminación. Era lo mismo que yo. Yo en Brasil lo primero que dije fue: "en Uruguay no hay racismo". Y ellos me dijeron: "¿cuántos coroneles tiene el ejército uruguayo y cuántos diputados, directores de escuela?" Ninguno. Ese tipo de preguntas nadie se la había hecho en Uruguay, yo creía que era "no llegan porque no quieren, porque no estudian" y los brasileros me empezaron a mostrar. Yo lo comprobé cuando trabajaba con la cuestión de los técnicos. Veía muchos porteros y limpiadoras negras en la oficina. Todo el mundo los quería pero ninguno de ellos se atrevía a competir con un blanco.

\section{-Con esa experiencia, ¿pudiste incorporarte con comodidad a la comunidad negra uruguaya?}

Ellos me hicieron ver muchas cosas que yo no había visto por no vivir en comunidad en esos barrios. Hay toda una vivencia comunitaria en torno al carnaval que en cuanto a vivencia comunitaria puede asemejarse a la brasileña. Yo nunca viví esa experiencia, había una diferencia cultural grande.

\section{¿No te integrabas?}

De ambas partes, creo... No te digo que me veían como una outsider pero yo era diferente... me hice una barra de amigos que era más jóvenes, iba a los conciertos, era muy amiga de [Rubén] Rada ${ }^{6}$ que era del barrio, me quedaba a dormir en la casa de algunos de ellos, tomaba, hacía lo mismo que ellos, pero al otro día, a las 7 de la mañana yo me iba a trabajar y ellos se quedaban en la rambla todo el día, en la playa. Había, por ejemplo una cuestión de machismo que yo no me la aguantaba y las mujeres la aceptaban, donde las mujeres

${ }^{6}$ Cantante, compositor y percusionista uruguayo conocido como El Negro Rada. 
son objetos de los hombres y ya, entonces, desde ese punto de vista, había problemas.

-Es decir que estabas entre un grupo de gente que no tenía nada que ver con vos, lo único que compartían era el color de la piel.

Sí. Y la joda.

-Entonces, cuando escribís sobre la mujer negra en tus poemas, no te estás refiriendo a vos.

No, en realidad no, o estoy escribiendo sobre cuando empecé a mirar lo étnico, las diferencias, pero no necesariamente mi persona.

-Porque en el prólogo a Memoria y Resistencia decís: "Por eso yo, Cristina, hablo de "resistencia"; porque ha sido mi cotidiano vivir en base a mi situación de madre pobre, latina y negra, en un mundo donde, digamos... no somos nosotros los que regimos".

Es que fue después de mi salida de Uruguay, o, digamos, después de mi concientización. A los 25 años yo estaba inmensamente feliz, viviendo bárbaro. Aunque si bien no tuve ningún problema con las monjas que me acuerde, sí le hice dos juicios al estado por racismo... ahora me estoy acordando, que tampoco fue todo maravilla.

- ¿Eso fue antes o después de Brasil?

No, después, antes capaz que no lo hubiera ligado al color.

- ¿Durante cuánto tiempo mantuviste el vínculo con la comunidad negra uruguaya a tu regreso de Brasil?

Hasta ahora seguimos siendo amigos, pero en práctica eso duró cinco años.

- ¿Y qué sentís que modificaste o conseguiste desde el punto de vista ideológico?

En esa época comienza Mundo afro ${ }^{7} .$. yo estoy desde que empieza Mundo afro.

\footnotetext{
${ }^{7}$ Organización uruguaya cuyo objetivo es luchar contra la discriminación y promover socioculturalmente a la comunidad afrouruguaya.
} 
-Si no te hubieras ido a Brasil quizás nunca te hubieras contactado con Mundo afro...

Yo creo que no, yo creo que no me hubiera interesado.

\section{-¿Cómo llegás a ellos?}

Desde la política. Mundo afro es de izquierda, nunca existieron como grupo afro, estaban en distintos partidos: comunista, socialista, etc. Pasado un tiempo se comienzan a juntar porque ya existía un grupo -que existe todavía- llamado ACSU, Asociación Cultural y Social de Uruguay, que era de negros pero era social, era para eventos culturales. La gente de Mundo afro sale de ahí y empieza a poner una connotación política, empieza a exigir derechos y a hablar de números en cuanto a estadísticas, a censos. Entonces, de ACSU, que era fundamentalmente cultural, se suman sobre todo dirigentes comunistas y se forma Mundo afro con esa connotación de clase y empiezan con algunos cuestionamientos de raza. Pero fue la clase lo que los movilizó, es decir, qué lugar ocupamos en la estructura social. Después empiezan muchos blancos a compartir, historiadores... Yo en ese momento, o me estaba por recibir de socióloga o ya era, no recuerdo, pero la cuestión de los números, del censo me interesaba muchísimo porque uno tiene que saber de qué está hablando cuando va a reclamar. En el Censo Nacional no existía el módulo "etnia". Yo era la que conversaba con la gente del centro para incluirlo y hoy en Uruguay existe.

-¿Etnia? Qué difícil me parece... ¿Y cómo se define?

Por la autopercepción...

-En esa época escribiste "25 de agosto de 1988 (Declaratoria de la independencia uruguaya)".

Efectivamente, allí hay una reflexión sobre la declaración de la independencia donde yo veo que estamos todos de marcha, en el centro de Montevideo y los tambores saliendo del Barrio Sur, sin habernos cuestionado que no nos liberamos de nada.

No debemos olvidar que somos hijos de reyes y de guerreros, por eso baten fuerte los tambores al nacer, en las bodas, en los funerales y hasta en las festividades nacionales celebradas con floridos blanqui-discursos que ignoran absolutamente lo concerniente a la participación del negro. Como hijos de reyes y guerreros 
resistimos desde hace siglos al emblanquecimiento, filosofía racista que ayer nos prohibía salir a la calle, y hoy, pretende mantenernos dispersos (De par en par).

-Hace un momento dijiste que no creés en las razas, sin embargo, hay una presencia constante de este tema en tu obra. No sólo en reflexiones de tipo histórico sino también en su intersección con el género.

Bueno, hay un patrón que yo he percibido y es que muchas mujeres negras tienen algo en común que es tener hijos solas, a veces cuando tienen al hombre son ellas las que los mantienen. Las mujeres negras en general son matriarcas y no lo veo tanto en la mujer blanca. Se percibe que la mujer negra es más fuerte... que soporta cosas que ya soportaron su madre y su abuela... Conozco muchísimas, una gran mayoría que son divorciadas o solteras y han hechos sus carreras con hijos y el padre negro desaparece o nunca estuvo...

\section{-¿De esta reflexión surge el poema "Memoria y resistencia", entonces?}

Exactamente.

Hombre Negro/ si tan solo buscas/ una mujer que caliente/ tu comida y tu cama/ sigue ocultando tus bellos ojos/ tras la venda blanca./ La de la lucha y los sueños/ es quien te habla./Ese es mi reino./ [...] Negro, / nuestro ausente de siempre, / generación tras generación, / yo te parí, / como a tu padre/ y a tus hermanos./ Yo curvé la espalda/sujetándote durante la cosecha; /sangro, lucho, resisto/ y desconoces mi voz./ [...]/ Yo:/ Madre, / Negra, /Cimarrona; / Iemanjá, / Oxúm, / e Iansá a la vez. (Memoria y resistencia).

Este poema surge de la experiencia, porque cuando llegué a Estados Unidos lo confirmé. Y veo que pasa en Brasil, en Uruguay, en Estados Unidos, y siempre con las mujeres negras y es por eso que [Barack] Obama al principio de su mandato llama al hombre negro a que sea padre porque los hogares están desestructurados. El hombre negro no asume su responsabilidad de padre, si se divorcia se divorcia del hijo también. Y sin embargo, sí lo están cuando se casan con una mujer blanca, no sé si es que lo perciben como un cambio de cultura, yo no sé qué es, pero sucede. Hay muchas cosas para reprocharle al hombre negro y yo con ese poema quería iniciar una discusión interna porque estaba en un grupo donde reclamábamos los derechos para 
los negros, entonces, yo digo: hay unos derechos para la mujer negra que son internos a la comunidad y no se discuten, como cuál es el lugar que el hombre negro le da a la mujer.

\section{-¿Y tuviste respuesta, hubo alguna reacción?}

Fue muy celebrado por las mujeres y algunos hombres negros, como dice en la dedicatoria ${ }^{8}$. Pero lo presenté en el Yari Yari en Nueva York, en 1997, un congreso de mujeres escritoras negras. Todo el mundo del ambiente literario estuvo ahí. Compartí la mesa con Nancy Morejón y fue muy fuerte porque yo a ella ya la conocía y la quería mucho pero no le había leído nada y cuando leí ese poema, Nancy lo alabó muchísimo y después que salimos me preguntó si había leído “Mujer negra”. Y yo le pregunté “¿de quién?..” "Mío”, me dice Nancy (risas). Bueno, la cuestión es que leo "Mujer negra" y me quería morir. Le dije que parecía que le había hecho un plagio pero ella me dijo que el punto es que las experiencias son similares porque somos mujeres negras, entonces percibimos las dos lo que ha sido nuestra historia y nuestra vida.

\section{$-¿ Y$ antes de irte a Estados Unidos, qué escritores afrolatinoamericanos leías?}

¡No! No conocía a ninguno. Marvin [Lewis] iba siempre a Uruguay y en el '92, '93, me invitó a un congreso que organizó en Missouri. Al lado mío estaba sentado Manuel Zapata Olivella a quien yo conocía porque iba siempre a Brasil. Pero no conocía a ninguno de los otros y estaban Argentina Chiriboga, Nelson Estupiñán Bas, Quincey Duncan, Zapata Olivella, Arnoldo Palacio, Nancy Morejón, críticos como Richard Jackson. Yo venía de leer coplas de autores antiguos afroargentinos, afrouruguayos, con un tema repetitivo, siempre volviendo al pasado, sin hacer una reflexión sobre los problemas presentes, como si todo el problema del negro hubiera quedado en el tiempo Juan Manuel de Rosas o José Artigas. Vi que esta gente podía competir en el mercado. Entonces fue empezar a escucharlos, ¡yo nunca había estado expuesta a esto de que hubiera críticos que ya se estuvieran por jubilar de hacer crítica literaria en relación con lo afro...! Yo no conocía a ninguno y le dije a Zapata "¿Vos conocés a todos éstos?" y me contestó "Sí, y te diría que los conozcas vos también". Era escuchar a toda esa gente hablando de cuestiones y problemas actuales del negro. Eso fue muy fuerte... fue decirme: "Cristina, si te querés dedicar a la literatura -en ese momento no se

8 "A las de siempre, / las pioneras/ las infatigables hijas de la Noche, / Mujeres Negras/ que ennoblecen la historia. /Y para aquellos hombres/que también lo hacen. Axé." 
me había pasado por la cabeza la crítica literaria- hay que hacerlo en serio, hay que leer más y ver, si sirve algo". Yo me sentía muy impactada, y me empecé a dar cuenta de mi pobre ignorancia. Porque me sabía toda la generación del '98, del '27, y nunca había escuchado a Zapata Olivella, por ejemplo, siendo que cuando yo lo conocí en Brasil se le hacía un homenaje, a pesar de que era de los pocos que no escribía en portugués. Cuando empecé a escuchar hablar... Zapata daba clases cuando hablaba, era un placer escucharlo.

\section{-A partir de ahí los comenzaste a leer, entonces.}

Sí, fue mi primer encuentro, fue donde quise pertenecer al grupo, vi que eran de distintos países del mundo y podíamos intercambiar cuestiones literarias. Ver que había gente que escribía sobre nosotros, fue muy fuerte... yo conocía a Marvin [Lewis] pero no había leído ninguno de sus libros. Era un mercado, un mundo que no conocía porque hasta ese momento no había publicado nada, salía alguna cosita en alguna revista pero no era demasiado en serio, sin embargo, y eso sí tengo que decirlo, la gente de Mundo afro sí lo había tomado en serio, en el sentido en que si tenían que referirse, -hasta el día de hoy ¿no?- a una escritora afrouruguaya se refieren a Cristina Cabral. Y eso fue desde antes, sabían que siempre andaba con un poema bajo el brazo.

\section{- ¿Vos creés que sos leída en Uruguay como en Estados Unidos?}

No, todo sale de Estados Unidos. Ellos tienen la plata como para armar todo.

\section{- ¿Por qué le dedicás el libro a Zapata?}

Él fue uno de los guías, como ha sido Marvin y como ha sido Bahía, es decir, son gente y lugares que me han despertado una chispa de algo, me han cuestionado algo, porque se dio que no solo los admiré como profesionales sino que empezamos una amistad. Ahora que murió Blas $^{9}$ yo no puedo volver a República Dominicana, porque para mí República Dominicana era él. Fue muy importante en mi vida, el poema "Cimarrones" surge de una conversación con Blas ${ }^{10}$.

[...] El africano que / es el que habita mi cuerpo / el que recorre la América mestiza / cargando cocos, semillas y tiempos. / [...] El que junto a las manos del indio / alzan

\footnotetext{
${ }^{9}$ Blas Jiménez, poeta dominicano fallecido en noviembre de 2009.

${ }^{10}$ El poeta dominicano escribió "Cimarrón", un poema que forma parte de su libro Exigencias de un cimarrón, luego convertido en obra teatral.
} 
sus voces, rugen al viento, / hemos roto las fronteras impuestas / mis hermanos indios / mis gemelos negros. / Fíjate bien, que no te confundan / los slogans publicitarios, / somos aquel mismo / africano cimarrón / en el camino del encuentro. (Desde mi trinchera).

Blas fue un hombre que toda la vida trabajó por la cuestión racial en República Dominicana y Haití y entonces, claro, él me cuestionó todo. Yo era muy linda en esa época, y Blas me llamaba la atención en esto, como los brasileños unos años antes, y me decía "tu realidad de mujer negra es muy light, muy suave, muy linda, porque aparte de todo lo que tuviste de educación y de familia, sos linda y entonces a la gente le caés bien". Yo pensaba que estaba loco, pero después de los años consideré que tenía parte de razón. "A una mujer bonita le das $30 \%$ de atención de entrada, pero esa ventaja tiene que trabajar a tu favor, tenés que decir cosas para nuestra gente, no escribas para los blancos, necesitamos gente que escriba para nuestra comunidad", me decía. Todo eso me fue quedando... qué es eso de nuestra gente, nuestra comunidad, cuál es mi comunidad, me llevó a todo un replanteo ¿no? No me sentía parte de eso, no había tenido las mismas vivencias. Tal vez Blas tampoco pero la situación de República Dominicana es distinta, tienen otra problemática interna con respecto a los negros, el racismo es brutal. Tal vez hasta ahora no tengo claro cuál es mi comunidad, ahora estoy en la fase de la vejez, como muchos, volcándome hacia el terreno holístico, ¿no?, mi comunidad es el mundo y tú la puedes integrar, no tienes por qué ser mujer negra y haber pasado por esas cosas... la gente de mi comunidad tiene valores que van más allá de lo étnico muy estricto, es gente que lucha por la paz, que trata de hacer una convivencia más pacífica en la tierra, sin importar de dónde sos, no creo más en los ismos, pienso que hemos sido rehenes de emblemas políticos, que fueron muy válidos y costaron mucha sangre y no sé qué se ha logrado, no quiero decir que esas muertes no valieron nada, sino que no hubo los cambios que ellos quisieron.

-De alguna manera es algo que siempre sostuviste a partir de tu educación y a pesar de aquel despertar de tu juventud en Brasil.

Mirá, yo no sé cuántas cosas incidieron en mí que lo racial nunca me dio tanto problema. Estoy convencida de que los racistas tienen un problema, el problema es de ellos, no mío, pero no me van a comer la cabeza con sus actitudes, paso de eso, paso... Yo no tengo problemas de racismo en cuanto a pareja, que es algo crucial. Aún hoy encuentro mujeres negras que jamás estarían con un blanco. Eso ya me ayudó a romper una cantidad de cadenas. El estudio... fui 
minoría donde estuve estudiando... esos problemas no los tengo, no me achica ir a pedir un empleo porque soy negra, me dirán que no pero no me impide ir. Me gustan los desafíos. Cuando vengo a ese primer congreso en Missouri estuve una primera semana en la Universidad de Indiana invitada por Carol Young, dando clases, visitando las cátedras, y un día que estaba nevando, salgo a fumar y empiezo a mirar la universidad, que es relativamente pequeña, pero me dije a mí misma: "yo voy a estudiar en una universidad así", lo que era una locura, casi imposible... Pero en lugar de decir "no me dejan entrar porque soy negra", se me ocurrió pensar qué hay que hacer para entrar acá, por qué yo no si acá entran millones. Siempre me ocupé en un plano de igualdad, ni más arriba ni más abajo, igual que el otro. Me costó dos años conseguir todo lo que hacía falta y fui a esa misma universidad. Vine con beca, me partí el alma, Silvia, sí, costó mucho, pero no tiene que ver con que haya sido negra. Pero yo no lo encaré así, yo no fui a buscar becas para negros... cuando entro a la universidad y una profesora me ve cómo soy, me dice "Cuidado que estás en Estados Unidos, esto no es Latinoamérica, aquí sos negra, así que tené cuidado, no te acerques a la gente de la misma manera porque va a haber gente que te acepta y gente que te rechaza". Y tuve un profesor racista, yo no lo podía creer, nunca había estado en contacto con un racista... tenía un cargo altísimo, además.

\section{- ¿Tenías compañeros negros?}

No. Y los que había en la universidad eran extranjeros. Y mirá vos que hay unas fiestas famosas que son muy elitistas, las fiestas de la fraternidad, de grupos blancos, el emblema blanco, son órdenes, hermandades de hombres, en casi todas las universidades existen. Hacen fiestas y es un lugar para crear conexiones y se juntan con otras hermandades que son de mujeres de la misma clase social. De ahí salen los casamientos, contratos de trabajo, etc. Yo salía de fiesta todos los sábados y recorría hermandades y donde la fiesta estaba mejor me quedaba. Aquella profesora no lo podía creer. Yo le decía "no tengo plata busco una fiesta y son gratis..." Me decía que tenga cuidado, que era peligroso, y yo le decía "me crié entre blancos".

\section{-Claro, pero el problema no es cómo te ves vos sino como te ven ellos.}

¡Exactamente lo que me dijo ella! "Es en el último lugar donde irían a buscarte porque no hay negros ahí. Si ves algo raro, andate". Entonces, Estados Unidos me vuelve a replantear el tema del ser negro de la forma más brutal, como se lo hizo a Zapata hace tantos años y él lo escribió en He visto la noche. Sin embargo, como te decía antes, estoy 
en otra etapa. En ese sentido, ya Zapata estaba en una etapa así, en su libro de Hemingway, en su retorno literario a África, lo veo más con esa filosofía del muntu universal, y su respeto por la vida, algo más global. Cuando me encuentro en un lugar rodeada de negros, y no tengo nada que decir por ellos... me digo "vamos a luchar por lo humano", yo ya pasé de lo racial, de lo político... a no ser que te encuentres en una situación extrema, como de apartheid...

\section{-¿Hablás de esto con algún escritor?}

Con Edelma ${ }^{11}$ (Zapata Olivella) tengo mucho contacto, o con escritores guineanos como Juan Tomás Ávila.

\section{- ¿Y cuál es la respuesta?}

Lo comparten totalmente, se adecuan al medio, al momento histórico que están viviendo, porque, por ejemplo, con Juan, de Guinea Ecuatorial: lo comparte totalmente pero cuando tenés el problema inmediato no podés estar en la trascendencia humanista, porque te matan, porque lo primario es sobrevivir, ése es un estadio para cuando ya has superado el anterior, no podés pensar en lo que es mejor para la humanidad en plena guerra, por ejemplo. Primero es sobrevivir.

\section{Bibliografía}

De-Costa Willis, M. (2003). Daughters of the Diaspora. Kingston, Jamaica: Ian Randle Publishers.

Rodríguez Cabral, C. (2004). Memoria \& Resistencia. Antología. Santo Domingo: Editora Manatí.

Valero, S. (2015). "Literatura y 'afrodescendencia': identidades políticas en la literatura afrolatinoamericana del siglo XXI", Revista de crítica literaria latinoamericana, $\mathrm{n}$ - 81, pp. 9-18.

Williams, L. (1995). “Entrevista con Cristina Rodriguez Cabral en Montevideo en julio de 1993", Afro Hispanic Review, no 14, pp. 57-63.

\footnotetext{
${ }^{11}$ Edelma, hija del escritor Manuel Zapata Olivella, falleció poco tiempo después de realizada esta entrevista.
} 